\title{
Understanding hypertriglyceridemia in women: clinical impact and management with prescription omega-3-acid ethyl esters
}

This article was published in the following Dove Press journal:

International Journal of Women's Health

8 March 2011

Number of times this article has been viewed

\section{Thomas D Dayspring}

North Jersey Institute of Menopausal Lipidology, Wayne, NJ, USA
Correspondence: Thomas D Dayspring

Director, North Jersey Institute

of Menopausal Lipidology,

516 Hamburg Turnpike, Suite 5,

Wayne, NJ 07470, USA

Tel + I 9737908604

Fax + I 973790 |488

Email tdayspring@aol.com
Background: Elevated triglycerides (TGs) are a common lipid disorder in the US and are associated with comorbidities such as pancreatitis, obesity, type 2 diabetes, and metabolic syndrome. TGs are generally elevated in postmenopausal women compared with premenopausal women. Meta-analysis has shown that elevated TGs are associated with an increased risk of coronary heart disease (CHD).

Objective: This article provides a general overview of TG metabolism and reviews data on the epidemiology and risk of elevated TGs in women, as pregnancy and menopause, in particular, have been associated with unfavorable changes in the lipoprotein profile, including elevations in TGs. In addition, this review seeks to explain the recommended TG goals and treatment options for hypertriglyceridemia with an emphasis on severe hypertriglyceridemia (TGs $\geq 500 \mathrm{mg} / \mathrm{dL}$ ) and its respective treatment with prescription omega-3-acid ethyl esters (P-OM3).

Methods: MedLine was searched for articles published through August 2009 using the terms "hypertriglyceridemia" and "dyslipidemia", with subheadings for "prevalence", "women", "treatment", "guidelines", "risk", and "omega-3 fatty acids". Publications discussing the epidemiology of hypertriglyceridemia, CHD risk, treatment guidelines for lipid management, or clinical trials involving P-OM3 were selected for review. The reference lists of relevant articles were also examined for additional citations.

Results: Hypertriglyceridemia is associated with increased CHD risk. Women, especially those with polycystic ovarian syndrome, type 2 diabetes, or who are postmenopausal, should be monitored regularly for the impact of hypertriglyceridemia on their lipid profile. Cardiovascular risk of TGs can be indirectly assessed by monitoring non-high-density lipoprotein cholesterol (non-HDL-C) levels. There are multiple sets of guidelines providing recommendations for desirable low-density lipoprotein cholesterol, TG, and non-HDL-C levels. Treatment of hypertriglyceridemia includes lifestyle interventions and, if needed, pharmacologic therapy. In patients with severe hypertriglyceridemia, P-OM3 can reduce TGs by up to $45 \%$.

Conclusion: Physicians should regularly monitor the lipid profile of their female patients. Any lipid abnormality should be managed promptly according to established guidelines. P-OM3 provide a well-tolerated option for the treatment of severe hypertriglyceridemia.

Keywords: triglycerides, Lovaza, P-OM3, women, lipids, omega-3

\section{Introduction}

Lipid abnormalities, including elevated cholesterol or triglyceride (TG) concentrations, are a common finding among adult patients in the US. Prior to 1996, abnormal TGs were an underappreciated lipid disorder in the US. ${ }^{1}$ However, over the past decade, TGs have gained prominence, both as an individual lipid measurement and for their effect on non-high-density lipoprotein cholesterol (non-HDL-C) levels. ${ }^{1,2}$ 
Although low-density lipoprotein cholesterol (LDL-C) is often used to assess dyslipidemia, it is now becoming clear that it is important to monitor and treat abnormal TG levels as well. ${ }^{3,4}$ Indeed, as an indirect measurement of apolipoprotein B (apo B)-containing TG-rich lipoproteins, the National Cholesterol Education Program (NCEP) Adult Treatment Panel III (ATP III) added non-HDL-C as a secondary goal of therapy in $2001 .^{5}$ This represents an emerging challenge for all health care practitioners treating female patients, including gynecologists, an increasingly popular choice as the primary care provider for many women. The increasingly fragmented approach to women's primary health care (ie, relegating some primary care by generalists and other primary care by gynecologists) adds complexity to overall women's health care, as it is unlikely that at any stage of life women receive comprehensive and systematic health care from only one provider. ${ }^{6}$

This article reviews the impact of elevated TGs in women and the importance of monitoring TG levels and other atherogenic surrogates in women. Guidelines for patient management are reviewed, as well as the evidence supporting the use of prescription omega-3-acid ethyl esters (P-OM3) as monotherapy for severe hypertriglyceridemia (TGs $\geq 500 \mathrm{mg} / \mathrm{dL}$ ) and in combination with statins in patients with persistently high TGs (200-499 mg/dL). Other treatment strategies, including diet and lifestyle modifications, are also discussed or mentioned.

\section{Methods}

MedLine was searched for articles published through August 2009 using the terms "hypertriglyceridemia" and "dyslipidemia", with subheadings for "prevalence", "women", "treatment", "guidelines", "risk", and "omega-3 fatty acids". Publications discussing the epidemiology of hypertriglyceridemia, coronary heart disease (CHD) risk, treatment guidelines for lipid management, or clinical trials involving P-OM3, were selected for review. The reference lists of relevant articles were also examined for additional citations.

\section{Triglyceride metabolism}

By facilitating trafficking of fatty acids (FAs), TGs play an important role in metabolism, serving as a molecular source of energy for muscles and other cells in the body. Excess FAs not needed for energy are reassembled into TGs and stored in adipose tissue. TGs, also known as triacylglycerols, comprise glycerol esterified with three FAs (acyl groups). TGs, along with other plasma-insoluble lipids such as cholesterol, cholesteryl ester, and phospholipids, are trafficked via protein-enwrapped particles called lipoproteins. ${ }^{7,8}$ TGs can be derived from two pathways, the exogenous (intestinal) pathway and the endogenous (hepatic-derived) pathway. ${ }^{7}$ Dietary consumption and absorption of FAs and glucose influence intestinal and hepatic metabolism of TGs. ${ }^{9}$

In the exogenous pathway, lipases hydrolyze dietary TGs throughout the upper gastrointestinal tract. Once absorbed into enterocytes, FAs are reassembled into TGs and incorporated into large, apoB48-enwrapped, TG-rich lipoproteins called chylomicrons. Chylomicrons enter the lymphatic system and ultimately the circulation, where they are exposed in muscular and adipocyte tissues to lipoprotein lipase (LPL), which hydrolyzes their core TGs, causing the release of FAs and surface phospholipids. The liver actively removes the remaining chylomicron remnants (TG-poor, cholesterol-rich particles) from circulation. ${ }^{10}$

In the endogenous pathway, hepatic TGs synthesized from FAs, and carbohydrate-derived glycerol and the other lipids, are packaged into apoB100-enwrapped very low-density lipoprotein (VLDL) particles. ${ }^{7}$ VLDL transports TGs from the liver to peripheral tissues, such as muscle and adipocytes. ${ }^{8}$ TG-rich particles shrink during lipolysis, and phospholipids, as well as certain apolipoproteins (apo C-I and -III and apo E), are exchanged with high density lipoproteins (HDL) particles. The remaining, now smaller, VLDL particles are termed remnants, or intermediate-density lipoproteins (IDLs), most of which are then removed from circulation by the liver LDL receptors. ${ }^{10}$ The remaining smaller VLDLs and IDLs undergo further lipolysis via hepatic lipase and are converted to LDL particles. ${ }^{7,8}$ Because of its long halflife of 2-3 days, the vast majority of apo B lipoproteins are LDLs. ${ }^{11,12}$ Increased numbers of apo B or LDL particles not cleared by hepatic LDL receptors have increased plasma residence time and may enter the arterial intima. ${ }^{13,14}$ Cholesterol is also trafficked in multiple directions to and from tissues via HDL. ${ }^{10,15}$

In patients with elevated TGs, VLDL particles are increased in number and size and contain more lipids, especially TGs. ${ }^{16}$ In insulin-resistant patients, these larger TG-rich VLDL particles have delayed lipolysis, which may be due to a lower affinity for lipase activity and tissue or hepatic receptors that promote the degradation and clearance of VLDL particles. ${ }^{17}$ These TG-rich VLDL particles with increased plasma residence time transfer some of their core TG to HDL and LDL via cholesteryl ester transfer protein (CETP), in exchange for cholesteryl ester (CE). ${ }^{13,17}$ CETP-mediated activity decreases the core CE content but 
increases the core TG content of HDL and LDL particles. Subsequent exposure of TG-rich, CE-poor HDL particles and LDL particles to hepatic lipase leads to the formation of small, dense LDL particles and HDL particles. ${ }^{18-20}$ Small, dense HDL particles are more likely to be degraded with their surface apo A-I excreted in the urine, reducing the capacity for HDL-mediated cholesterol clearance. ${ }^{15}$ Small, dense LDL particles are not readily cleared by LDL receptors and therefore accumulate, which leads to increased LDL particle (apo B) numbers. ${ }^{8,20}$

In patients with normal hepatic TG pools, VLDL particles are smaller in size and number, and CETP activity is decreased, lessening the transfer of TGs to LDL and HDL particles, resulting in greater LDL particle core cholesterol composition, which may increase LDL-C levels. ${ }^{7}$

\section{Triglycerides in women Epidemiology}

The classification for assessing CVD risk related to TG levels according to the NCEP ATP III defines fasting TGs $<150 \mathrm{mg} / \mathrm{dL}$ as normal, TG levels $150-199 \mathrm{mg} / \mathrm{dL}$ as moderately high risk, TG levels $200-499 \mathrm{mg} / \mathrm{dL}$ as high risk, and TG levels $\geq 500 \mathrm{mg} / \mathrm{dL}$ (severe hypertriglyceridemia, also referred to as very high TGs) as very high risk. ${ }^{21}$ According to the National Health and Nutrition Examination Survey (NHANES) 1999-2004, about 29.6\% of US women

\section{TG/Female Mean values-different age-groups}

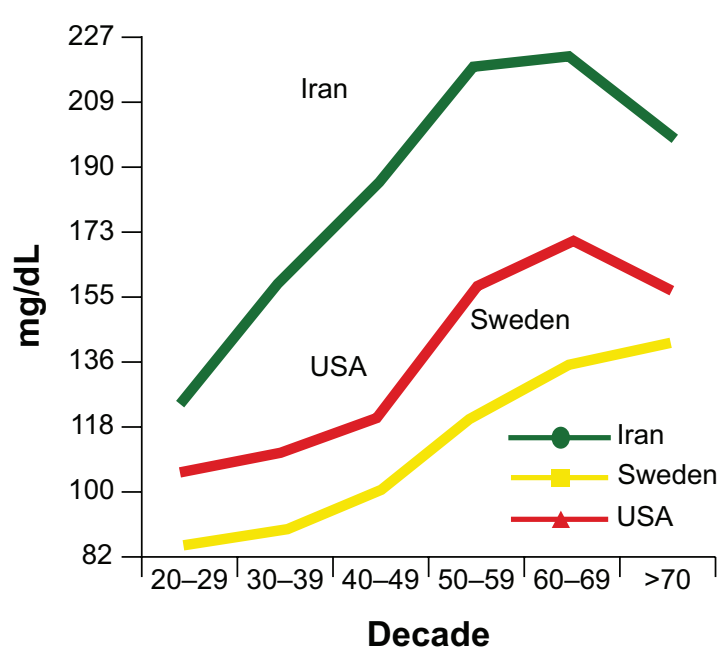

(age 20 years and older) have hypertriglyceridemia (TGs $>150 \mathrm{mg} / \mathrm{dL}$ ). In the US, severe hypertriglyceridemia (TGs $\geq 500 \mathrm{mg} / \mathrm{dL}$ ) occurs in about $1.7 \%$ (3.8 million) of diagnosed patients, and in about $0.8 \%$ (1.2 million) of all US females. ${ }^{1}$ An analysis of the Framingham Heart Study showed that the $61 \%$ of women who had incident CHD had TGs $>200 \mathrm{mg} / \mathrm{dL} .{ }^{22}$ Severe hypertriglyceridemia arises from multiple causes, including rare genetic mutations that reduce the expression of LPL and/or apo C-II (Fredrickson type I and $\mathrm{V}$ hyperlipidemia), as well as very poorly controlled or acute onset of diabetes, nephrosis, or certain drugs. ${ }^{21}$ More modest increases in TGs in women are seen with insulin resistance, type 2 diabetes (affects about 19 million people in the US), pregnancy, obesity, high-carbohydrate diets, alcohol use, hypothyroidism, and metabolic disorders (especially the polycystic ovarian syndrome), as well as the use of some prescription drugs, including antipsychotics (clozapine, olanzapine), $\beta$-blockers (atenolol, metropolol), and anti-inflammatories, among others..$^{23,24}$

\section{Changes in triglyceride levels in menopausal women}

Metabolic changes associated with menopause and aging can be a major cause of abnormal lipid profiles in women. ${ }^{25}$ An analysis of subjects in the NHANES 1999-2002 cohort reveals that although women have lower

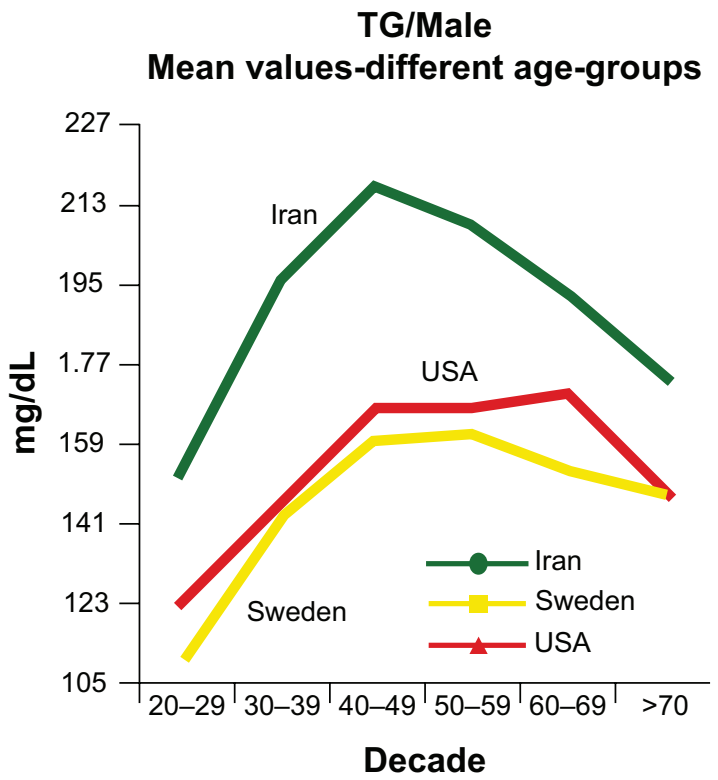

Figure I Influence of aging on TG levels of men and women in three cultures. All TG values between the ethnic groups are significant $(P<0 / 00 \mathrm{I})$ except between Sweden and the US $(P=0.65)$. In Iranians, the combination of high TG was associated with elevated apo $B$, suggesting that increased hepatic fatty acid flux may be an important driver of the increased apo B. The increased numbers of TG-rich VLDL result in relative enrichment of LDL and HDL in TG and depletion in cholesterol ester and therefore higher apo B and apo A-I than LDL-C and HDL-C, respectively. Copyright @ 2009 . Elsevier. Reprinted with permission from Solhpour A, Parkhideh S, Sarrafzadegan N, et al. Levels of lipids and apolipoproteins in three cultures. Atherosclerosis. 2009;207(I):200-207. ${ }^{26}$

Abbreviations: Apo B, apolipoprotein B; HDL, high-density lipoprotein; HDL-C, high-density lipoprotein cholesterol; LDL, low-density lipoprotein; LDL-C, low-density lipoprotein cholesterol; TG, triglyceride; VLDL, very low-density lipoprotein. 
TGs than men throughout most of their life, a reversal happens in women above 60 years of age (Figure 1). ${ }^{26,27}$ Postmenopausal women tend to have higher levels of TGs compared with premenopausal women. ${ }^{28}$ TGs can be significantly influenced by menopausal status and folliclestimulating hormone levels. ${ }^{29}$ Aging has also been shown to increase TG levels. ${ }^{29}$ These TG increases are likely associated with insulin resistance related to age, menopausal status, weight increase, and obesity. ${ }^{29,30}$ The transition through menopause is associated with selective deposition of visceral fat. ${ }^{31}$ Abdominal visceral fat deposition best predicts changes in lipid parameters and insulin sensitivity. ${ }^{32}$ Increased LPL activity is observed after the withdrawal of estrogens, ${ }^{32}$ which leads to the elevation of the FAs locally and accumulation of abdominal fat. ${ }^{25}$

\section{Clinical impact}

TGs are a significant risk factor for CHD irrespective of LDL-C levels and other established risk factors. ${ }^{3,33}$ In addition, the combination of enlarged waist circumference $(\geq 88 \mathrm{~cm}$ or 35 inches) and elevated TGs ( $\geq 128 \mathrm{mg} / \mathrm{dL})$ can also be a useful marker of CVD risk in postmenopausal women. ${ }^{34}$ Similar to elevated levels of fasting TGs, very high levels of nonfasting TGs may also indicate the presence of increased numbers of atherogenic apo B particles, including remnant lipoproteins and LDL, which can increase CVD risk. ${ }^{35}$ Hypertriglyceridemia is also related to low HDL-C levels, another independent CVD risk factor, and both of these lipid abnormalities are components of the metabolic syndrome. $3,36,37$

Hypertriglyceridemia is the third leading cause of acute pancreatitis after gallstone disease and alcohol. Severe TG levels $\geq 1000 \mathrm{mg} / \mathrm{dL}$ are associated with approximately $10 \%$ of all acute pancreatitis episodes and half of all cases of gestational pancreatitis. It has been suggested that high levels of circulating TG-rich lipoproteins are hydrolyzed by pancreatic lipase into FAs. The elevation in serum FAs may induce the formation of FAs, phospholipid micelles, and subsequent inflammation due to the disruption of platelets and the vascular endothelium. Hyperviscosity due to elevated serum FAs may also aggravate this condition. ${ }^{38}$

\section{Reducing triglyceride levels in women Goals of therapy}

Plasma cholesterol measurements are strong predictors of atherogenesis. ${ }^{21}$ However, the measurement of apo $\mathrm{B}$ provides an estimate of the total burden of particles considered most atherogenic, and the use of apo B or LDL particle concentrations has been shown to be a stronger predictor of CVD risk than any other lipid concentration. ${ }^{39}$ LDL-C, VLDL-C (calculated as TG/5), and, in particular, non-HDL-C lipid concentrations serve as surrogates of apo $\mathrm{B}$ concentration. ${ }^{40}$ However, non-HDL-C is a better surrogate of all atherogenic particles than LDL-C, as it includes cholesterol within all apo B-containing particles. ${ }^{21}$ The non-HDL-C value can be calculated easily by subtracting the HDL-C value from the total cholesterol (TC) value and can be assessed in the nonfasting patient. ${ }^{2}$ Data from the Framingham Heart Study indicate that non-HDL-C is a better predictor of CVD risk than LDL-C, regardless of TG levels. ${ }^{40}$

According to NCEP ATP III guidelines (Table 1), in patients with hypertriglyceridemia (TGs 200-499 mg/dL), LDL-C is the primary target for therapy, with non-HDL-C as a secondary treatment goal. ${ }^{21}$ LDL-C goals range from $<70 \mathrm{mg} /$ $\mathrm{dL}$ in very high-risk patients to $<100 \mathrm{mg} / \mathrm{dL}$ for patients with CHD or CHD equivalents and to $160 \mathrm{mg} / \mathrm{dL}$ for those without CHD risk factors. ${ }^{41}$ Non-HDL-C treatment goals are $30 \mathrm{mg} / \mathrm{dL}$ (which represents a normal VLDL-C level) higher than LDL-C goals stratified by CHD risk. ${ }^{21}$ In patients with severe hypertriglyceridemia (defined in guidelines as very high TGs [TGs $\geq 500 \mathrm{mg} / \mathrm{dL}]$ ), lowering TGs is the first priority, and reducing CHD risk (LDL-C and non-HDL-C levels) is a secondary goal, once TG levels are reduced to $<500 \mathrm{mg} / \mathrm{dL}$. ${ }^{4,21}$

The American Heart Association (AHA) guidelines to prevent CVD in women (Table 2) state that non-HDL-C of $<130 \mathrm{mg} / \mathrm{dL}$ is desirable. ${ }^{42}$ In a patient who has reached her LDL-C goal but still has a high level of non-HDL-C, indicating a high level of apo $\mathrm{B}$ particles, residual risk remains. ${ }^{39,44}$ For patients with cardiometabolic risk factors, including diabetes, hypertriglyceridemia, and low HDL-C, the American Diabetes Association (ADA) and American

Table I NCEP ATP III goals for LDL-C and non-HDL-C in patients with elevated TGs, stratified by CHD risk level ${ }^{20,41}$

\begin{tabular}{lll}
\hline Risk level & LDL-C & Non-HDL-C \\
\hline CVD plus high-risk factors & $<70 \mathrm{mg} / \mathrm{dL}$ & $<100 \mathrm{mg} / \mathrm{dL}$ \\
CHD or CHD risk equivalent & $<100 \mathrm{mg} / \mathrm{dL}$ & $<130 \mathrm{mg} / \mathrm{dL}$ \\
Multiple (2+) risk factors & $<130 \mathrm{mg} / \mathrm{dL}$ & $<160 \mathrm{mg} / \mathrm{dL}$ \\
$0-1$ risk factors & $<160 \mathrm{mg} / \mathrm{dL}$ & $<190 \mathrm{mg} / \mathrm{dL}$ \\
\hline
\end{tabular}

Note: aNCEP ATP III recommends non-HDL-C as a secondary treatment goal in patients with TGs $\geq 200 \mathrm{mg} / \mathrm{dL}$. Risk factors include age, smoking, hypertension, premature family history of CHD, and low HDL-C.

Abbreviations: $\mathrm{CHD}$, coronary heart disease; CVD, cardiovascular disease; HDL-C, high-density lipoprotein cholesterol; LDL-C, low-density lipoprotein cholesterol; NCEP ATP III, National Cholesterol Education Program Adult Treatment Panel III; TGs, triglycerides. 
Table 2 Selected statements from American Heart Association guidelines for the prevention of coronary heart disease in women

\begin{tabular}{|c|c|}
\hline Lifestyle changes & Statement \\
\hline Smoking cessation & $\begin{array}{l}\text { Do not smoke and avoid } \\
\text { environmental tobacco smoke }\end{array}$ \\
\hline Physical activity & $\begin{array}{l}\text { Minimum of } 30 \text { minutes of } \\
\text { moderate-intensity physical activity } \\
\text { on most, and preferably all, days of } \\
\text { the week }\end{array}$ \\
\hline Dietary intake & $\begin{array}{l}\text { A diet rich in fruits and vegetables; } \\
\text { choose whole-grain, high-fiber } \\
\text { foods; consume fish, especially } \\
\text { oily fish, at least twice a week; } \\
\text { limit intake of saturated fat to } 10 \% \\
\text { of energy and, if possible, to } 7 \% \text {, } \\
\text { cholesterol to } 300 \mathrm{mg} / \mathrm{d}\end{array}$ \\
\hline Alcohol intake & No more than one drink per day \\
\hline Weight maintenance/reduction & $\begin{array}{l}\text { Women should maintain or lose } \\
\text { weight through an appropriate } \\
\text { balance of physical activity, caloric } \\
\text { intake, and formal behavioral } \\
\text { programs when indicated to } \\
\text { maintain/achieve a BMl between } \\
18.5 \text { and } 24.9 \mathrm{~kg} / \mathrm{m}^{2} \text { and a waist } \\
\text { circumference of } 35 \text { inches }\end{array}$ \\
\hline Omega-3 fatty acids & $\begin{array}{l}\text { As an adjunct to diet, omega- } 3 \text { fatty } \\
\text { acids in capsule form (approximately } \\
850-1000 \text { mg of EPA and DHA) } \\
\text { may be considered in women with } \\
\text { CHD, and higher doses ( } 2-4 \mathrm{~g} \text { ) may } \\
\text { be used for treatment of women } \\
\text { with high triglyceride levels }\end{array}$ \\
\hline
\end{tabular}

Treatment goals
Major risk factor interventions Lipid and lipoprotein levels: optimal levels and lifestyle

The following levels of lipids and lipoproteins in women should be encouraged through lifestyle approaches:

LDL-C $<100 \mathrm{mg} / \mathrm{dL}$

$\mathrm{HDL}-\mathrm{C}>50 \mathrm{mg} / \mathrm{dL}$

Triglycerides $<150 \mathrm{mg} / \mathrm{dL}$

Non-HDL-C $<1360 \mathrm{mg} / \mathrm{dL}$

Notes: Copyright (c) 2007. Wolters Kluwer/Lippincott, Williams \& Wilkins. Reprinted with permission from Mosca L, Banka CL, Benjamin EJ, et al. Evidencebased guidelines for cardiovascular disease prevention in women: 2007 update. Circulation. 2007; I I5(II):| |48I-I50I. 42

Abbreviations: BMI, body mass index; CHD, coronary heart disease; DHA, docosahexaenoic acid; EPA, eicosapentaenoic acid; HDL-C, high-density lipoprotein cholesterol; LDL-C, low-density lipoprotein cholesterol.

College of Cardiology have established LDL-C, non-HDL-C, and apo B treatment goals (Table 3 ) and state that in patients with cardiometabolic risk, pharmacological decisions should be made with consideration of their effect on apo B levels. ${ }^{39}$

\section{Current management practices}

During patient visits, physicians must be diligent in educating women regarding cardiovascular health, along with informing
Table 3 Summary of Lipid and Lipoprotein treatment recommendations from $A D A / A C C F^{39}$ and $A A C C .^{72}$

\begin{tabular}{|c|c|c|c|c|}
\hline \multicolumn{5}{|c|}{ Treatment goals } \\
\hline $\begin{array}{l}\text { Highest-risk } \\
\text { level }\end{array}$ & LDL-C & Non-HDL-C & Apo B & LDL-P \\
\hline ADA/ACC & $<70 \mathrm{mg} / \mathrm{dL}$ & $<100 \mathrm{mg} / \mathrm{dL}$ & $<80 \mathrm{mg} / \mathrm{dL}$ & - \\
\hline AACC & $<70 \mathrm{mg} / \mathrm{dL}$ & $<80 \mathrm{mg} / \mathrm{dL}$ & - & - \\
\hline \multicolumn{5}{|c|}{ High-risk patients } \\
\hline $\mathrm{ADA} / \mathrm{ACC}$ & $<100 \mathrm{mg} / \mathrm{dL}$ & $<130 \mathrm{mg} / \mathrm{dL}$ & $<90 \mathrm{mg} / \mathrm{dL}$ & - \\
\hline AACC & $<100 \mathrm{mg} / \mathrm{dL}$ & $<120 \mathrm{mg} / \mathrm{dL}$ & $<80 \mathrm{mg} / \mathrm{dL}$ & I $100 \mathrm{nmol} / \mathrm{L}$ \\
\hline
\end{tabular}

Lower-risk patients

AACC $\quad<130 \mathrm{mg} / \mathrm{dL} \quad<150 \mathrm{mg} / \mathrm{dL} \quad 100 \mathrm{mg} / \mathrm{dL} \quad 1400 \mathrm{nmol} / \mathrm{L}$

Abbreviations: LDL-C, low-density lipoprotein cholesterol; non-HDL-C, non-highdensity lipoprotein cholesterol; Apo, apolipoprotein; LDL-P, LDL particle count; AACC, American Association of Clinical Chemistry

women that regular lipid assessments and proper management of lipid abnormalities are an important part of their overall health care. A recent national telephone-based survey revealed that confusion generated by the media (ie, inconsistent efforts by the media to faciliatate cardiovascular health awareness campaigns) is a major barrier to cardiovascular health in women ( $49 \%$ of respondents). In addition, $36 \%$ of respondents do not perceive themselves to be at risk for $\mathrm{CHD}$, and $25 \%$ of respondents reported that their health care provider did not discuss the importance of heart health. Approximately $20 \%$ of respondents also reported that health care providers did not clearly explain how they could improve their risk status. ${ }^{45}$ It is important that health care providers clearly explain cardiovascular risks to their female patients and also discuss how to reduce these risks through appropriate diet and lifestyle changes. ${ }^{46}$

Although reducing LDL-C, a surrogate of apo $B$, has been a focus of managing lipid-related risk, it may not address the apo B particles related to TG elevation, such as remnants, small LDL particles, and TG-rich LDL. Overlooking the rest of the lipid profile can lead to the underdiagnoses and undertreatment of atherogenic apo B particles, particularly in women. ${ }^{22,47}$ In the US, only about one-third of physicians accept and use non-HDL-C measurements. ${ }^{47}$ Increased efforts may be necessary to educate physicians about the importance of monitoring non-HDL-C in women. It is likely that the NCEP ATP IV, due for release in 2011, will elevate the importance of non-HDL-C.

\section{Lifestyle and diet modification}

Changes in lifestyle habits are first-line therapy for all lipid disorders, including elevated TGs, and include body 
weight control, regular physical activity, smoking cessation, restriction of alcohol use (in selected persons), and avoidance of high-carbohydrate diets. ${ }^{21}$ The AHA recommends that women should accumulate at least 30 minutes of moderately intense physical activity (eg, brisk walking) preferably daily, and more exercise to lose weight. ${ }^{42}$

The NCEP ATP III dietary guidelines call for caloric intake that meets daily needs without exceeding them, limited consumption of saturated and monounsaturated fats and carbohydrates, and increased consumption of fiber and plant stanols/sterols. ${ }^{21}$ However, more current evidence has questioned dietary supplementation with plant sterols. ${ }^{48}$ As part of adopting a healthy diet, multiple health associations, including the $\mathrm{AHA},{ }^{49}$ the $\mathrm{ADA},{ }^{50}$ and the US Departments of Agriculture and Health and Human Services, ${ }^{51}$ recommend regular consumption of fatty fish (salmon, tuna, herring, sardines, mackerel, and trout) that provides the omega-3 FAs docosahexaenoic acid (DHA) and eicosapentaenoic acid (EPA). Eating 8 oz of fatty fish in a week provides an average of $\sim 500 \mathrm{mg} / \mathrm{d}$ DHA and EPA. ${ }^{52}$ In 1992, the AHA further recommended 2-4 g/d DHA and EPA (under a physician's care) for patients trying to lower TGs. ${ }^{53}$ However, newer data show that P-OM3 have a threshold effect on lowering TGs, and a dose of $4 \mathrm{~g} / \mathrm{d}$ is required. Like other TG-modulating drugs, greater reductions are seen in those with high TGs concentrations of $>500 \mathrm{mg} / \mathrm{dL} \cdot{ }^{54}$ Obtaining $4 \mathrm{~g} / \mathrm{d}$ of DHA and EPA through diet alone would require the consumption of $\sim 32-64$ oz of fatty fish in a week, ${ }^{54}$ which may be an impractical solution for many patients. In addition, due to concerns regarding mercury and other environmental contaminants in dietary fish, supplementation may be a more reasonable way to provide fish oil to patients. ${ }^{55} \mathrm{OM} 3-\mathrm{FAs}$ are also available in a variety of nonregulated dietary supplements. The use of purified and concentrated P-OM3 (four capsules/day, $1 \mathrm{~g}$ each) for patients with severe hypertriglyceridemia may improve compliance and reliability compared with dietary supplements containing fish oil, which may contain as little as $300 \mathrm{mg}$ of DHA and EPA. ${ }^{55,56}$

\section{Pharmacologic treatment options}

In spite of dietary and lifestyle modifications, some patients require the use of medication to achieve non-HDL-C and TG treatment goals. In patients with multiple lipid abnormalities and TGs $<500 \mathrm{mg} / \mathrm{dL}$, statins, at the dose required to achieve risk-adjusted goals, are recommended as first-line therapy after lifestyle interventions have been offered. ${ }^{21}$ As an alternative option, lower-dose statins in combination with fibrates or niacin can be used. Adding ezetimibe to statins can also help achieve goals, ${ }^{58}$ and bile acid sequestrants can be added if the TGs are $<200 \mathrm{mg} / \mathrm{dL}$. ${ }^{21}$ Statin-treated patients who have not achieved non-HDL-C goals should be offered additional lifestyle modifications or a higher statin dose. ${ }^{21}$ However, it should be noted that patients treated with statin monotherapy often meet LDL-C goals (61\%) but may be less likely to meet both LDL-C and non-HDL-C goals (39\%). ${ }^{57}$ The addition of a fibrate, niacin, ezetimibe, or P-OM3 might be considered to help patients treated with a statin achieve non-HDL-C goals. ${ }^{21,58,59}$

For patients with severe hypertriglyceridemia (TGs $\geq$ $500 \mathrm{mg} / \mathrm{dL}$ ), therapeutic options recommended to lower TGs include $4 \mathrm{~g} / \mathrm{d}$ P-OM3, fibrates, high doses of niacin, and, if needed, high doses of statins (both niacin and fibrates have cautionary regulatory labeling relative to their use with statins). ${ }^{21}$ Although elevated TGs should be treated promptly, no evidence from well-controlled, blinded studies has shown that decreasing TGs per se with P-OM3 $4 \mathrm{~g} / \mathrm{d}$ or any other medication reduces CVD risk. ${ }^{21,39}$

\section{Prescription omega-3-acid ethyl esters for the treatment of severe hypertriglyceridemia Monotherapy}

For treatment of severe hypertriglyceridemia, only one prescription formulation of P-OM3 (Lovaza ${ }^{\circledR}$, a registered trademark of Reliant Pharmaceuticals, Inc., a member of the GlaxoSmithKline group of companies, Research Triangle Park, NC, USA) is US Food and Drug Administration (FDA) approved. Each $1 \mathrm{~g}$ capsule contains at least $900 \mathrm{mg}$ P-OM3 (of which DHA comprises $\sim 375 \mathrm{mg}$ and EPA $\sim 465 \mathrm{mg}$ ) ${ }^{60}$ $\mathrm{P}-\mathrm{OM} 3$ monotherapy is indicated as an adjunct to diet for adults only with severe hypertriglyceridemia (TGs $\geq$ $500 \mathrm{mg} / \mathrm{dL}$ ). The FDA-approved $4 \mathrm{~g} / \mathrm{d}$ dose significantly lowers TG and non-HDL-C levels, which appears to be due primarily to VLDL-C reduction, in patients with severe hypertriglyceridemia. ${ }^{61-63}$

The effects of P-OM3 $4 \mathrm{~g} / \mathrm{d}$ monotherapy for lowering TGs in adult patients ( $\mathrm{N}=84 ; 42$ on $\mathrm{P}-\mathrm{OM} 3$ and 42 on placebo) with severe hypertriglyceridemia were evaluated in two randomized, double-blind, placebo-controlled, parallel-group studies of 6 and 16 weeks' duration. ${ }^{61,62}$ In a pooled analysis of both monotherapy studies, baseline TG levels ranged from $500 \mathrm{mg} / \mathrm{dL}$ to $2000 \mathrm{mg} /$ dL with a median TG concentration of $792 \mathrm{mg} / \mathrm{dL}$. Baseline median HDL-C and calculated LDL-C levels in these patients were $23 \mathrm{mg} / \mathrm{dL}$ and $100 \mathrm{mg} / \mathrm{dL}$, respectively. ${ }^{61}$ Treatment with $4 \mathrm{~g} / \mathrm{d}$ P-OM3 resulted in median reductions of TGs, VLDL-C, 
and non-HDL-C of $44.9 \%, 41.7 \%$, and $13.8 \%$, respectively, and increases in LDL-C and HDL-C of $44.5 \%$ and $9.1 \%$, respectively, from baseline levels (Figure 2). ${ }^{61}$ Patients treated with placebo had a median TG increase of $6.7 \%$ and reductions in VLDL-C, non-HDL-C, LDL-C, and HDL-C of $0.9 \%, 3.6 \%, 4.8 \%$, and $0.0 \%$, respectively, from baseline levels (Figure 2). ${ }^{61}$

Patients included in this pooled analysis had type IV or V hypertriglyceridemia, characterized by elevated cholesterol and TG levels associated with increased concentration of VLDL, and decreased HDL-C and LDL-C. ${ }^{61,62}$ Significant TG reductions in patients with hypertriglyceridemia are often accompanied by similar reductions in VLDL-C. LDL-C may increase in these patients, presumably due to more effective and rapid lipolysis and clearing of VLDL and IDL. ${ }^{63}$ Reduction in VLDL-TGs reduces CETP activity, resulting in larger and more normally composed (more CE-rich, TG-poor) LDLs and HDLs, which also helps explain the rise in LDL-C and HDL-C and decrease in VLDL-C. This can also result in a net reduction in the aggregate levels of nonHDL-C. The largest increases in LDL-C can be expected to occur in patients with the highest baseline TG levels prior to P-OM3 therapy. ${ }^{63} \mathrm{~A}$ similar LDL-C increase of $45 \%$ has been observed when fenofibrate was used to treat patients with type IV and V hypertriglyceridemia. ${ }^{64}$ Despite the reduction in VLDL-C, there is little change in apo B levels with P-OM3 therapy. ${ }^{59,65}$ As with any lipid-regulating product, LDL-C levels should be monitored periodically during therapy with P-OM3. ${ }^{60}$

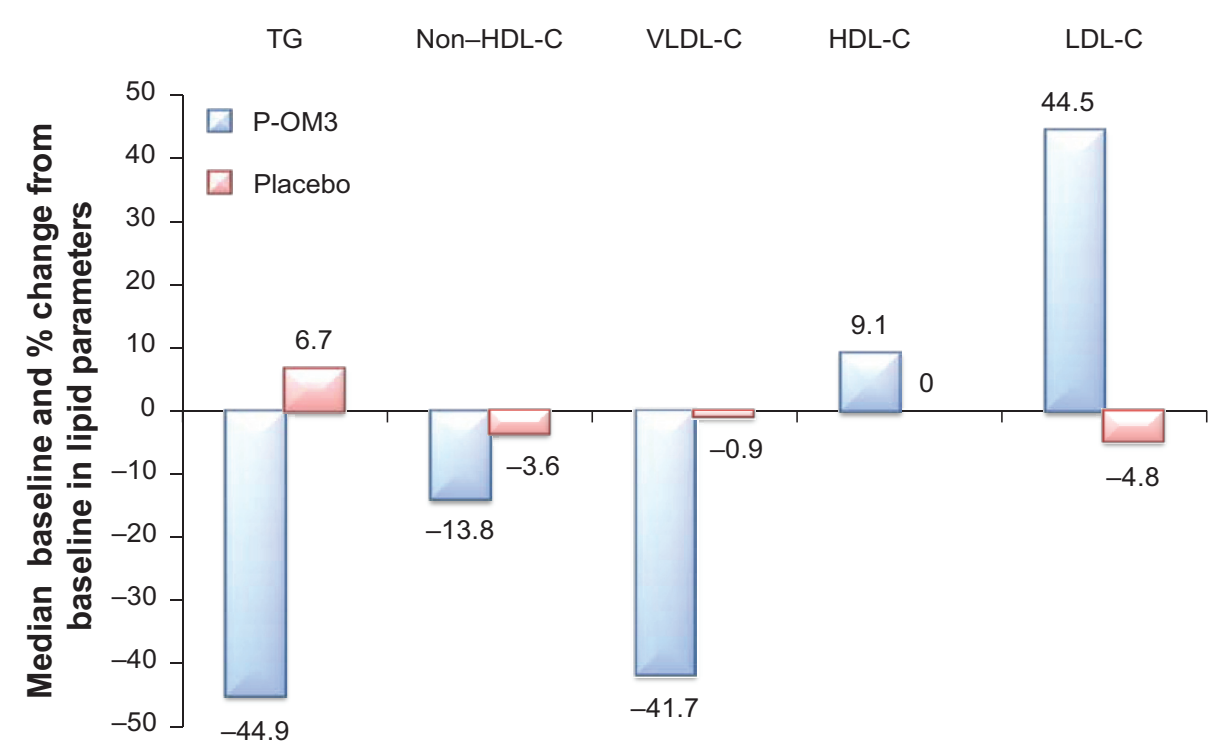

Figure 2 Effect of P-OM3 vs placebo on lipid parameters in patients with severe hypertriglyceridemia. $P$ values for lipid changes were TGs $(P<0.0000 \mathrm{I})$, VLDL-C $(P<0.000 \mathrm{I})$, HDL-C $(P=0.014)$, and LDL-C $(P=0.0014)$. Copyright $\odot$ 2009. GlaxoSmithKline group of companies. Adapted with permission from Copyright $\subseteq$ 2009. GlaxoSmithKline group of companies. Adapted with permission from LOVAZA [prescribing information]. Research Triangle Park, NC: GlaxoSmithKline; 2009.60

Abbreviations: HDL-C, high-density lipoprotein cholesterol; LDL-C, low-density lipoprotein cholesterol; P-OM3, prescription omega-3-acid ethyl esters; TG, triglyceride; VLDL-C, very low-density lipoprotein cholesterol.

\section{Combination therapy with statins}

Patients with elevated TGs typically have an increase in atherogenic VLDL remnants. Therefore, the residual risk in people with high TG levels cannot be accounted for by LDL-C measurements alone and should be monitored by measuring non-HDL-C (VLDL-C+LDL-C). ${ }^{2,21}$ In patients with hypertriglyceridemia (TGs 200-499 mg/dL), NCEP ATP III guidelines state that LDL-C is the primary goal, with non-HDL-C as a secondary target for therapy. ${ }^{21}$ When LDL-C is not significantly elevated, the goal for non-HDL-C with TG-lowering agents can be obtained more easily. ${ }^{21}$

Studies have also demonstrated that the addition of P-OM3 to statin therapy leads to further reductions in non-HDL-C. In a randomized, placebo-controlled study, COMBOS (Combination of Prescription Omega-3 Plus Simvastatin), patients $(\mathrm{N}=254)$ who had attained a mean LDL-C level below or within $10 \%$ of the patient's NCEP goal with persistently high TGs (200-499 mg/dL) while taking simvastatin $40 \mathrm{mg} / \mathrm{dL}$ for 8 weeks were randomized to add P-OM3 $4 \mathrm{~g} / \mathrm{d}$ or placebo to their ongoing simvastatin therapy for an additional 8 weeks. ${ }^{59}$ At baseline, in patients treated with P-OM3, median TG, LDL-C, and non-HDL-C levels were $268 \mathrm{mg} / \mathrm{dL}, 91 \mathrm{mg} / \mathrm{dL}$, and $137 \mathrm{mg} / \mathrm{dL}$, respectively. At the end of therapy, adding P-OM3 to the simvastatin treatment regimen reduced median non-HDL-C by $9 \%$ (vs 2.2\% with placebo; $P<0.001$; Figure 3 ). ${ }^{59}$ Subjects treated with P-OM3 also had a greater decrease in median apo $\mathrm{B}$ concentrations beyond that induced by the statin alone 


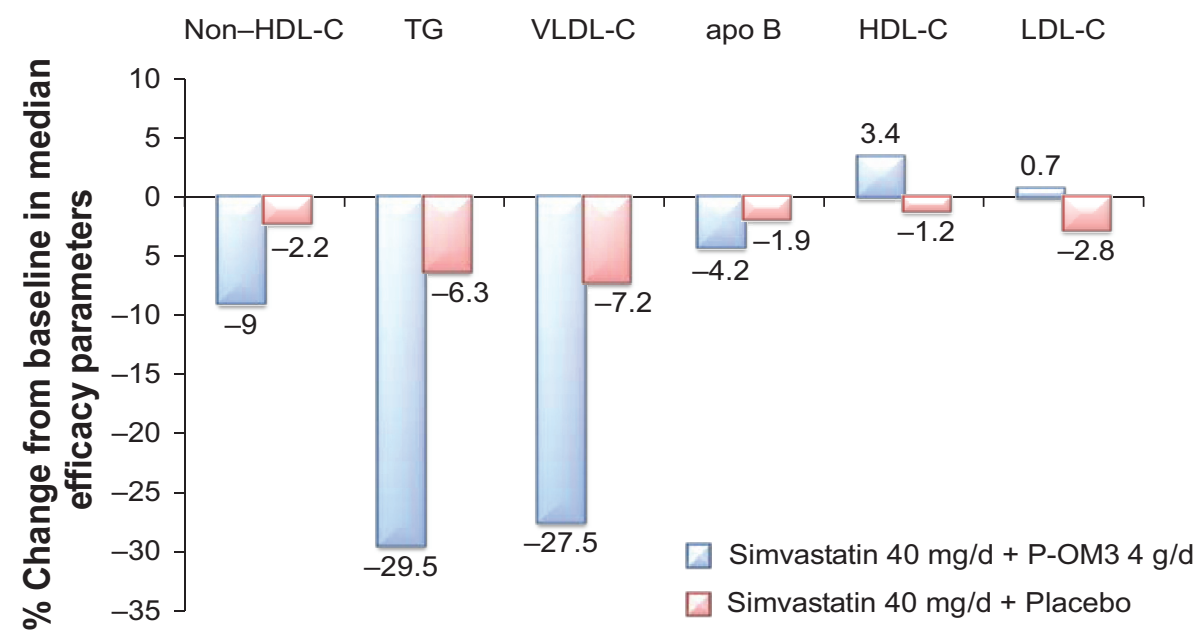

Figure 3 Response to the addition of P-OM3 $4 \mathrm{~g} / \mathrm{d}$ to ongoing simvastatin $40 \mathrm{mg} / \mathrm{d}$ therapy in patients with hypertriglyceridemia (TGs $\geq 200 \mathrm{mg} / \mathrm{dL}$ and $\leq 499 \mathrm{mg} / \mathrm{dL}$ ). Values for differences of non-HDL-C, HDL-C, TGs, and VLDL-C between POM3 and placebo were all significant at $P<0.00 \mathrm{I}$ and for apo B $P=0.023$. The LDL-C differences were not significant. Copyright (C) 2007. Elsevier. Adapted with permission from Davidson MH, Stein EA, Bays HE, et al. Efficacy and tolerability of adding prescription omega-3 fatty acids $4 \mathrm{~g} / \mathrm{d}$ to simvastatin $40 \mathrm{mg} / \mathrm{d}$ in hypertriglyceridemic patients: an 8-week, randomized, double-blind, placebo-controlled study. Clin Ther. 2007;29(7): $1354-1367.59$

Abbreviations: Apo B, apolipoprotein B; HDL-C, high-density lipoprotein cholesterol; LDL-C, low-density lipoprotein cholesterol; P-OM3, prescription omega-3-acid ethyl esters; TG, triglyceride; VLDL-C, very low-density lipoprotein cholesterol.

(4.2\% vs $1.9 \% ; P=0.023) .{ }^{59}$ An open-label extension study in this persistently high TG (200-499 $\mathrm{mg} / \mathrm{dL})$ cohort was conducted to analyze the long-term safety and efficacy of simvastatin $40 \mathrm{mg} / \mathrm{dL}$ and P-OM3 $4 \mathrm{~g} / \mathrm{d}$ combination therapy for up to 24 months. ${ }^{66}$ Eligible patients included those who completed the multicenter, randomized, placebo-controlled, double-blind, parallel-group study. ${ }^{66}$ "Switchers" were patients who received placebo+simvastatin who were switched to P-OM3+simvastatin $(\mathrm{n}=100)$. "Nonswitchers" were patients who were assigned $\mathrm{P}-\mathrm{OM} 3+$ simvastatin in COMBOS who remained on their original therapy $(n=88) .{ }^{66}$ The difference between switchers and nonswitchers in median percentage change in non-HDL-C from COMBOS end of treatment to month 4 of the extension study was the primary endpoint of this study. ${ }^{66}$ There was a greater response among switchers at month 4. Median percentage change in non-HDL-C from end of treatment was $-9.4 \%$ versus $0.9 \%$ for switchers and nonswitchers $(P<0.001)$, respectively. ${ }^{66}$ Median percentage change for switchers and nonswitchers combined at months 4 and 12 was $-8.3 \%$ and $7.3 \%$, respectively. At month 24 , the median percent change in non-HDL-C for the combined groups was $-8.9 \% .{ }^{67}$ Data indicate that sustained reductions in non-HDL-C occurred with longer-term treatment with P-OM3+simvastatin. ${ }^{66}$

An additional analysis of subjects from the original trial, examining the effects of P-OM3 $4 \mathrm{~g} / \mathrm{d}$ cotherapy with simvastatin $40 \mathrm{mg} / \mathrm{d}$ on lipoprotein particle concentrations, revealed that the addition of P-OM3 significantly reduced mean VLDL particle size and increased LDL particle size compared with placebo ( $P<0.006$ for both). HDL particle size was not altered in these subjects. The total concentrations of VLDL particles or LDL particles relative to placebo were not significantly changed; however, large VLDL particle and IDL particle concentrations were lowered ( $P<0.01$ for both). Total LDL-P was not affected, but the large LDL particle concentration (LDL-P) was increased and small LDL-P was reduced compared with placebo $(P<0.0001) .{ }^{67}$ Remnant-like particle cholesterol, apo C-III, and Lp-PLA2 concentrations (factors associated with increased atherogenesis and CVD risk) were reduced compared with placebo (all $P<0.003$ ), ${ }^{67}$ the effects of which are consistent with those typically seen in hypertriglyceridemic subjects. ${ }^{68}$ It is unknown which of these effects, if any, represent the direct effect of P-OM3.

Simultaneous initiation of simvastatin and P-OM3 treatment can also lead to a greater reduction in non-HDL-C than treatment with simvastatin alone. A randomized, placebo-controlled trial was conducted in which 39 patients with persistently high TGs (200-600 mg/dL) were given simvastatin $20 \mathrm{mg} / \mathrm{d}$ plus P-OM3 $4 \mathrm{~g} / \mathrm{d}$ or placebo and then crossed over to the other treatment after 6 weeks. ${ }^{69}$ Cotherapy with simvastatin plus P-OM3, when compared with simvastatin plus placebo, produced greater median reductions in TGs $(43.6 \%$ vs $28.7 \%$; $P<0.001)$, TC (31\% vs $26.4 \%$; $P<0.01)$, and non-HDL-C (40\% vs $34.3 \% ; P<0.001)$, whereas P-OM3 did not provide additional benefits for LDL-C (37.2\% vs 38.4\%). ${ }^{69}$ There was no difference in median apo B reduction between simvastatin and P-OM3 treatment when compared with simvastatin plus placebo. ${ }^{69}$ 
In an open-label extension of this study, 14 participants were treated with P-OM3 $4 \mathrm{~g} / \mathrm{d}$ plus simvastatin $80 \mathrm{mg} / \mathrm{d}$ for another 6 weeks. ${ }^{70}$ The increase in statin dosage led to a further reduction in non-HDL-C (51.0\% with $\mathrm{P}-\mathrm{OM} 3$ plus simvastatin $80 \mathrm{mg} / \mathrm{d}$ vs $40.8 \%$ with P-OM3 plus simvastatin $20 \mathrm{mg} / \mathrm{d} ; P<0.05)$ without affecting TGs $(58.6 \%$ with P-OM3 plus simvastatin $80 \mathrm{mg} / \mathrm{d}$ vs $54.7 \%$ with P-OM3 plus simvastatin $20 \mathrm{mg} / \mathrm{d}){ }^{70}$

In addition, the effects of adding P-OM3 or placebo to escalating doses of atorvastatin (10-40 mg/d) on non-HDL-C and TG levels were assessed in 243 patients with baseline non-HDL-C $>160 \mathrm{mg} / \mathrm{dL}$ and TGs $250-599 \mathrm{mg} / \mathrm{dL} .^{71}$ Patients received escalating doses of open-label atorvastatin according to the following dosing schedule: weeks $0-8=10 \mathrm{mg} / \mathrm{d}$, weeks $9-12=20 \mathrm{mg} / \mathrm{d}$, and weeks $13-16=40 \mathrm{mg} / \mathrm{d}$. Patients were blinded with respect to receiving P-OM3 $4 \mathrm{~g} / \mathrm{d}$ or placebo for 16 weeks. P-OM3 plus atorvastatin 10,20 , and $40 \mathrm{mg} /$ day led to $6.5 \%(P=0.0002)$, $7.9 \%(P<0.0001)$, and $4.1 \%(P=0.0007)$ greater reductions in median non-HDL-C when compared with placebo plus the same doses of atorvastatin at the end of 8,12 , and 16 weeks, respectively. In addition, $\mathrm{P}-\mathrm{OM} 3$ plus atorvastatin reduced median TC, TGs, and VLDL-C and increased HDL-C levels to a significantly greater extent than placebo plus atorvastatin. Non-HDL-C efficacy was also noninferior to doubling the statin dose in patients receiving P-OM3 plus atorvastatin. ${ }^{71}$ The results to date demonstrate that treatment with P-OM3 is efficacious and well tolerated as monotherapy or as part of a combination therapy to reduce TG levels in patients with hypertriglyceridemia.

\section{Conclusion}

Hypertriglyceridemia is a common lipid abnormality in the US that becomes more prevalent in women after menopause. Additional metabolic influences, including aging, central visceral obesity, and insulin resistance, can also negatively impact a woman's lipid profile. Treatment of severe hypertriglyceridemia (TGs $\geq 500 \mathrm{mg} / \mathrm{dL}$ ) should be a priority for all affected patients. Dietary and lifestyle interventions, including weight control, regular physical activity, smoking cessation, restricted alcohol use, and low-carbohydrate diets with increased intake of oily fish, represent the first-line option for therapy. In many cases, patients with severe hypertriglyceridemia require pharmacologic intervention. P-OM3 and fibrates are both FDA-approved options for the treatment of severe hypertriglyceridemia in adult patients. As discussed in the previous paragraphs, $\mathrm{P}-\mathrm{OM} 3$ has been shown to be well tolerated and effective as monotherapy for reducing TG levels in patients with severe hypertriglyceridemia. Primary care physicians and obstetricians/gynecologists assuming a primary care role should discuss regular lipid panel testing with their patients. The NCEP recommends monitoring lipid profiles every 5 years unless the profile is abnormal, then more frequent monitoring is called for, which may include lipoprotein testing in patients with cardiometabolic risk. Regular evaluations of female patients' lipid parameters, including TGs and non-HDL-C, as well as apo B and LDL particle concentrations, will allow for more comprehensive evaluation and treatment of lipid disorders in this population, which has historically been undertreated.

\section{Acknowledgments}

The listed author meets the criteria for authorship set forth by the International Committee for Medical Journal Editors. The author wishes to acknowledge the following individuals for their critical review during the development of this manuscript: Doug Wicks MPH, Susan Johnson MD, Rosemary Schroyer MS, and Amy Meadowcroft PharmD, all of whom are employees of GlaxoSmithKline. Editorial support in the form of development of the draft outline and the first draft of the manuscript, editorial suggestions to draft versions of this paper, assembling tables and figures, collating author comments, copyediting, fact checking, and referencing was provided by Marcus Lynch PhD and Amanda McGeary MS, at AlphaBioCom, LLC, and was funded by GlaxoSmithKline.

\section{Disclosure}

The author reports the following association with GSK: Advisor and Speaker's Bureau

\section{References}

1. Ford ES, Li C, Zhao G, et al. Hypertriglyceridemia and its pharmacologic treatment among US adults. Arch Int Med. 2009;169(6):572-578.

2. Blaha M, Blumenthal R, Brinton E, Jacobson T. The importance of non-HDL cholesterol reporting in lipid management. J Clin Lipidol. 2008;2(4):267-273

3. Castelli WP. Epidemiology of triglycerides: a view from Framingham. Am J Cardiol. 1992;70(19):3H-9H.

4. Knopp RH, Paramsothy P, Atkinson B, Dowdy A. Comprehensive lipid management versus aggressive low-density lipoprotein lowering to reduce cardiovascular risk. Am J Cardiol. 2008;101(8A): 48B-57B

5. Expert Panel on Detection, Evaluation, and Treatment of High Blood Cholesterol in Adults (Adult Treatment Panel III). Executive summary of the third report of the National Cholesterol Education Program (NCEP). JAMA. 2001;285(19):2486-2497.

6. Henderson JT, Weisman CS. Women's patterns of provider use across the lifespan and satisfaction with primary care coordination and comprehensiveness. Med Care. 2005;43(8):826-833.

7. Packard CJ, Demant T, Stewart JP, et al. Apolipoprotein B metabolism and the distribution of VLDL and LDL subfractions. J Lipid Res. 2000; 41:305-317. 
8. Bays H. Rationale for prescription omega-3-acid ethyl ester therapy for hypertriglyceridemia: a primer for clinicians. Drugs Today (Barc). 2008;44(3):205-246.

9. Lichtenstein AH. Thematic review series: patient-oriented research. Dietary fat, carbohydrate, and protein: effects on plasma lipoprotein patterns. J Lipid Res. 2006;47(8):1661-1667.

10. Rader D, Hobbs H. Chapter 350. Disorders of lipoprotein metabolism. In: Fauci A, Braunwald E, Kasper D, et al, eds. Harrison's Principles of Internal Medicine. http://www.accessmedicine.com/content. aspx?aID=2882429. Accessed January 12, 2011.

11. Brewer HB Jr. Hypertriglyceridemia: changes in the plasma lipoproteins associated with an increased risk of cardiovascular disease. Am J Cardiol. 1999;83(9B):3F-12F.

12. Langer T, Strober W, Levy RI. The metabolism of low density lipoprotein in familial type II hyperlipoproteinemia. J Clin Invest. 1972;51(6): 1528-1536.

13. Caslake MJ, Packard CJ. Phenotypes, genotypes and response to statin therapy. Curr Opin Lipidol. 2004;15(4):387-392.

14. El Harchaoui K, van der Steeg W, Stroes E, et al. Value of low-density lipoprotein particle number and size as predictors of coronary artery disease in apparently healthy men and women: the EPIC-Norfolk Prospective Population Study. J Am Coll Cardiol. 2007;49(5):547-553.

15. Dayspring T. High-density lipoproteins: emerging knowledge. Cardiometab Syndr. 2007;2(1):59-62.

16. Georgieva AM, van Greevenbroek MM, Krauss RM, et al. Subclasses of low-density lipoprotein and very low-density lipoprotein in familial combined hyperlipidemia: relationship to multiple lipoprotein phenotype. Arterioscler Thromb Vasc Biol. 2004;24(4):744-749.

17. Grundy SM. Hypertriglyceridemia, insulin resistance, and the metabolic syndrome. Am J Cardiol. 1999;83(9B):25F-29F.

18. Guerin M, Le Goff W, Lassel TS, et al. Atherogenic role of elevated CE transfer from HDL to VLDL(1) and dense LDL in type 2 diabetes: impact of the degree of triglyceridemia. Arterioscler Thromb Vasc Biol. 2001;21(2):282-288.

19. Grundy SM. Hypertriglyceridemia, atherogenic dyslipidemia, and the metabolic syndrome. Am J Cardiol. 1998;81(4A):18B-25B.

20. Toth PP, Dayspring TD, Pokrywka GS. Drug therapy for hypertriglyceridemia: fibrates and omega-3 fatty acids. Curr Atheroscler Rep. 2009;11(1):71-79.

21. Expert Panel on Detection, Evaluation, and Treatment of High Blood Cholesterol in Adults (Adult Treatment Panel III). Third report of the National Cholesterol Education Program (NCEP) Expert Panel on Detection, Evaluation, and Treatment of High Blood Cholesterol in Adults (Adult Treatment Panel III) final report. Circulation. 2002; 106(25):3143-3421.

22. Lloyd-Jones DM, O’Donnell CJ, D'Agostino RB, et al. Applicability of cholesterol-lowering primary prevention trials to a general population: the Framingham Heart Study. Arch Int Med. 2001;161(7):949-954.

23. Mosca LJ. Optimal management of cholesterol levels and the prevention of coronary heart disease in women. Am Fam Phys. 2002;65(2): 217-226.

24. American Diabetes Association. Winning at work: diabetes facts. http:// www.diabetes.org/communityprograms-and-localevents/waw-diabetesfacts.jsp. Accessed January 2, 2011.

25. Kolovou GD, Bilianou HG. Influence of aging and menopause on lipids and lipoproteins in women. Angiology. 2008;59(Suppl 2):54S-57S

26. Solhpour A, Parkhideh S, Sarrafzadegan N, et al. Levels of lipids and apolipoproteins in three cultures. Atherosclerosis. 2009;207(1):200-207.

27. Carroll MD, Lacher DA, Sorlie PD, et al. Trends in serum lipids and lipoproteins of adults, 1960-2002. JAMA. 2005;294(14):1773-1781.

28. Derby CA, Crawford SL, Pasternak RC, et al. Lipid changes during the menopause transition in relation to age and weight: the Study of Women's Health Across the Nation. Am J Epidemiol. 2009;169(11): 1352-1361.

29. Carr M. The emergence of the metabolic syndrome with menopause. $J$ Clin Endocrinol Metab. 2003;88(6):2404-2411.
30. Sowers M, Zheng H, Tomey K, et al. Changes in body composition in women over six years at midlife: ovarian and chronological aging. $J$ Clin Endocrinol Metab. 2007;92(3):895-901.

31. Piche ME, Lapointe A, Weisnagel SJ, et al. Regional body fat distribution and metabolic profile in postmenopausal women. Metab Clin Exp. 2008;57(8):1101-1107.

32. Tchernof A, Desmeules A, Richard C, et al. Ovarian hormone status and abdominal visceral adipose tissue metabolism. J Clin Endocrinol Metab. 2004;89(7):3425-3430.

33. Sarwar N, Danesh J, Eiriksdottir G, et al. Triglycerides and the risk of coronary heart disease: 10,158 incident cases among 262,525 participants in 29 Western prospective studies. Circulation. 2007; 115(4): 450-458.

34. Tanko LB, Bagger YZ, Qin G, et al. Enlarged waist combined with elevated triglycerides is a strong predictor of accelerated atherogenesis and related cardiovascular mortality in postmenopausal women. Circulation. 2005;111(15):1883-1890.

35. Nordestgaard BG, Benn M, Schnohr P, Tybjaerg-Hansen A. Nonfasting triglycerides and risk of myocardial infarction, ischemic heart disease, and death in men and women. JAMA. 2007;298(3):299-308.

36. Ford ES, Giles WH, Dietz WH. Prevalence of the metabolic syndrome among US adults: findings from the third National Health and Nutrition Examination Survey. JAMA. 2002;287(3):356-359.

37. Assmann G, Schulte H, Funke H, von Eckardstein A. The emergence of triglycerides as a significant independent risk factor in coronary artery disease. Eur Heart J. 1998;19(Suppl M):M8-M14.

38. Ewald N, Hardt PD, Kloer HU. Severe hypertriglyceridemia and pancreatitis: presentation and management. Curr Opin Lipidol. 2009; 20(6):497-504.

39. Brunzell JD, Davidson M, Furberg CD, et al. Lipoprotein management in patients with cardiometabolic risk: consensus statement from the American Diabetes Association and the American College of Cardiology Foundation. Diabetes Care. 2008;31(4):811-822.

40. Liu J, Sempos CT, Donahue RP, et al. Non-high-density lipoprotein and very-low-density lipoprotein cholesterol and their risk predictive values in coronary heart disease. Am J Cardiol. 2006;98(10):1363-1368.

41. Grundy SM, Cleeman JI, Merz CN, et al. Implications of recent clinical trials for the National Cholesterol Education Program Adult Treatment Panel III guidelines. Circulation. 2004;110(2):227-239.

42. Mosca L, Banka CL, Benjamin EJ, et al. Evidence-based guidelines for cardiovascular disease prevention in women: 2007 update. Circulation. 2007;115(11):1481-1501

44. Dayspring T, Helmbold A. You have a new job: monitor the lipid profile. OBG Management. 2008;20(12):227-239.

45. Mosca L, Mochari H, Christian A, et al. National study of women's awareness, preventive action, and barriers to cardiovascular health. Circulation. 2006;113(4):525-534.

46. Cooke CE, Hammerash WJ Jr. Retrospective review of sex differences in the management of dyslipidemia in coronary heart disease: an analysis of patient data from a Maryland-based health maintenance organization. Clin Ther. 2006;28(4):591-599.

47. Stein EA, Sniderman A, Laskarzewski P. Assessment of reaching goal in patients with combined hyperlipidemia: low-density lipoprotein cholesterol, non-high-density lipoprotein cholesterol, or apolipoprotein B. Am J Cardiol. 2005;96(9A):36K-43K; discussion 34K-35K.

48. Weingartner O, Lutjohann D, Ji S, et al. Vascular effects of diet supplementation with plant sterols. J Am Coll Cardiol. 2008;51(16): 1553-1561.

49. Lichtenstein AH, Appel LJ, Brands M, et al. Diet and lifestyle recommendations revision 2006: a scientific statement from the American Heart Association Nutrition Committee. Circulation. 2006;114(1): 82-96.

50. Bantle JP, Wylie-Rosett J, Albright AL, et al. Nutrition recommendations and interventions for diabetes: a position statement of the American Diabetes Association. Diabetes Care. 2008;31(Suppl 1): S61-S78. 
51. US Department of Health and Human Services and US Department of Agriculture. Dietary guidelines for Americans, 2005. 6th ed. Washington, DC: US Government Printing Office; 2005.

52. Kris-Etherton PM, Innis S. American Dietetic Association, Dietitians of Canada. Position of the American Dietetic Association and Dietitians of Canada: dietary fatty acids. J Am Diet Assoc. 2007;107(9): 1599-1611.

53. Kris-Etherton PM, Harris WS, Appel LJ. Fish consumption, fish oil, omega-3 fatty acids, and cardiovascular disease. Circulation. 2002; 106(21):2747-2757.

54. Jacobson TA. Role of n-3 fatty acids in the treatment of hypertriglyceridemia and cardiovascular disease. Am J Clin Nutr. 2008;87(6): 1981S-1990S.

55. Oh RC, Beresford SA, Lafferty WE. The fish in secondary prevention of heart disease (FISH) survey: primary care physicians and omega3 fatty acid prescribing behaviors. J Am Board Fam Med. 2006;19(5): 459-467.

56. Harris WS. n-3 fatty acids and serum lipoproteins: human studies. Am J Clin Nutr. 1997;65(Suppl 5):1645S-1654S.

57. Davidson MH, Maki KC, Pearson TA, et al. Results of the National Cholesterol Education (NCEP) Program Evaluation ProjecT Utilizing Novel E-Technology (NEPTUNE) II survey and implications for treatment under the recent NCEP Writing Group recommendations. Am J Cardiol. 2005;96(4):556-563.

58. Davidson MH, Ballantyne CM, Kerzner B, et al. Efficacy and safety of ezetimibe coadministered with statins: randomised, placebo-controlled, blinded experience in 2382 patients with primary hypercholesterolemia. Int J Clin Pract. 2004;58(8):746-755.

59. Davidson MH, Stein EA, Bays HE, et al. Efficacy and tolerability of adding prescription omega-3 fatty acids $4 \mathrm{~g} / \mathrm{d}$ to simvastatin $40 \mathrm{mg} / \mathrm{d}$ in hypertriglyceridemic patients: an 8-week, randomized, double-blind, placebo-controlled study. Clin Ther. 2007;29(7):1354-1367.

60. LOVAZA [prescribing information]. Research Triangle Park, NC: GlaxoSmithKline; 2009

61. Harris WS, Ginsberg HN, Arunakul N, et al. Safety and efficacy of Omacor in severe hypertriglyceridemia. J Cardiovasc Risk. 1997; 4(5-6):385-391.

62. Pownall HJ, Brauchi D, Kilinc C, et al. Correlation of serum triglyceride and its reduction by omega-3 fatty acids with lipid transfer activity and the neutral lipid compositions of high-density and low-density lipoproteins. Atherosclerosis. 1999;143(2):285-297.
63. Bays HE, Tighe AP, Sadovsky R, Davidson MH. Prescription omega-3 fatty acids and their lipid effects: physiologic mechanisms of action and clinical implications. Expert Rev Cardiovasc Ther. 2008;6(3): 391-409.

64. Goldberg AC, Schonfeld G, Feldman EB, et al. Fenofibrate for the treatment of type IV and V hyperlipoproteinemias: a double-blind, placebocontrolled multicenter US study. Clin Ther. 1989;11(1):69-83.

65. Calabresi L, Donati D, Pazzucconi F, et al. Omacor in familial combined hyperlipidemia: effects on lipids and low density lipoprotein subclasses. Atherosclerosis. 2000;148(2):387-396.

66. Bays H, Maki K, McKenney J, et al. Long-term up to 24 month efficacy and safety of concomitant prescription omega-3-acid ethyl esters and simvastatin in hypertriglyceridemic patients. Curr Med Res Opin. 2010; 26(4):907-915.

67. Davidson M, Maki K, Bays H, et al. Effects of prescription omega-3-acid ethyl esters on lipoprotein particle concentrations, apolipoproteins AI and CIII, and lipoprotein associated phospholipase A2 mass in statin-treated subjects with hypertriglyceridemia. J Clin Lipidol. 2009;3(5): 332-340.

68. Ginsberg HN, Zhang YL, Hernandez-Ono A. Regulation of plasma triglycerides in insulin resistance and diabetes. Arch Med Resear. 2005; 36(3):232-240.

69. Maki KC, McKenney JM, Reeves MS, et al. Effects of adding prescription omega-3 acid ethyl esters to simvastatin ( $20 \mathrm{mg} /$ day $)$ on lipids and lipoprotein particles in men and women with mixed dyslipidemia. Am J Cardiol. 2008;102(4):429-433.

70. Maki K, Lubin B, Reeves M, Dicklin M, et al. Prescription omega-3 acid ethyl esters plus simvastatin 20 and $80 \mathrm{mg}$ : effects in mixed dyslipidemia. J Clin Lipidol. 2009;3(1):33-38.

71. Bays H, McKenney J, Maki KC, et al. Prescription omega-3-acid ethyl esters: effects on non-high-density lipoprotein cholesterol in combined hyperlipidemic patients when co-administered with escalating doses of atorvastatin. Mayo Clin Proc. 2010;85:122-128.

72. Contois JH, McConnell JP, Sethi AA, et al. Apolipoprotein B and Cardiovascular Disease Risk: Position Statement from the AACC Lipoproteins and Vascular Diseases Division Working Group on Best Practices. Clinical Chemistry. 2009;55:3:407-419.
International Journal of Women's Health

\section{Publish your work in this journal}

The International Journal of Women's Health is an international, peerreviewed open-access journal publishing original research, reports, reviews and commentaries on all aspects of women's healthcare including gynecology, obstetrics, and breast cancer. Subject areas include: Chronic conditions (migraine headaches, arthritis, osteoporosis);

\section{Dovepress}

Endocrine and autoimmune syndromes; Sexual and reproductive health; Psychological and psychosocial conditions. The manuscript management system is completely online and includes a very quick and fair peer-review system. Visit http://www.dovepress.com/ testimonials.php to read real quotes from published authors. 